\title{
JARINGAN SYARAF TIRUAN UNTUK MEMPREDIKSI LAJU PERTUMBUHAN PENDUDUK MENGGUNAKAN METODE BACPROPAGATION (STUDI KASUS DI KOTA BENGKULU)
}

\author{
Aji Sudarsono ${ }^{1)}$ \\ 1) Program Studi Teknik Informatika Fakultas Ilmu Komputer Universitas Dehasen Bengkulu \\ Jl. Meranti Raya No. 32 Kota Bengkulu 38228 Telp. (0736) 22027, 26957 Fax. (0736) 341139 \\ 1) ajisudarsono27@gmail.com
}

\begin{abstract}
This research was conducted to study the neural networks with backpropagation implemented with Matlab. Where data collected through direct observation. And data to be entered are grouped based on factors that influence in predicting the population growth rate. Neural Network was formed by determining the number of units of each layer. Once the network is formed conducted training of the data that has been grouped. The test is conducted with the software Matlab experiments conducted with network architecture that consists of the input unit, the unit hidden layer and output unit. the results obtained from these tests is the value of each architecture Performance and epochs are not equal. The test results are displayed in graphs comparing the target value with the value of training.
\end{abstract}

Keywords: Neural Network Backpropagation, Prediction Population Growth Rate

\section{INTISARI}

Penelitian ini dilakukan untuk mempelajari Jaringan Syaraf Tiruan dengan Backpropagation yang diimplementasikan dengan Matlab. Di mana data yang dikumpulkan melalui observasi secara langsung. Dan data yang akan diinputkan dikelompokkan berdasarkan faktor yang mempengaruhi dalam memprediksi laju pertumbuhan penduduk tersebut. Kemudian dibentuk Jaringan Syaraf Tiruan dengan menentukan jumlah unit setiap lapisan. Setelah jaringan terbentuk dilakukan training dari data yang telah dikelompokkan tersebut. Pengujiannya dilakukan dengan perangkat lunak Matlab percobaan yang dilakukan dengan arsitektur jaringan yang terdiri dari unit masukan, unit layer tersembunyi dan unit keluarannya. hasil yang didapat dari pengujian tersebut adalah niali Performance dan epochs setiap arsitektur tidak sama. Hasil pengujiannya ditampilkan dalam bentuk grafik perbandingan nilai target dengan nilai pelatihan.

Kata Kunci: Jaringan Syaraf Tiruan Backpropagation, Prediksi Laju Pertumbuhan Penduduk

\section{PENDAHULUAN}

Pemanfaatan teknologi infomasi yang semakin maju pada saat ini, Jaringan Syaraf Tiruan (Artificial Neural Network) dapat digunakan untuk memprediksi tingkat pertumbuhan penduduk.

Teknologi informasi merupakan suatu teknologi yang digunakan untuk mengelola data, memproses, mendapatkan, menyusun, menyimpan, memanipulasi data dalam berbagai cara untuk menghasilkan informasi yang berkualitas, yaitu informasi yang relevan, akurat dan tepat waktu, yang digunakan untuk keperluan pribadi, bisnis, swasta dan pemerintah yang merupakan informasi yang strategis dalam pengambilan keputusan. Menurut Wiliam dan Li, penggunaan ANN dengan algoritma training back-propagation untuk melakukan prediksi pacuan kuda di Jamaika. ANN dengan jenis feed forward network atau Backpropagationyang digunakan dalam penelitian ini telah terbukti memberikan hasil yang baik untuk keperluan prediksi.
Dengan banyaknya pekerjaan yang harus dikerjakan oleh Badan Pusat Statistik (BPS) Kota Bengkulu dan terkadang kebutuhan data yang mendesak, sehingga untuk memprediksi laju pertumbuhan penduduk diperlukan suatu sistem yang dapat memprediksi tingkat pertumbuhan penduduk tersebut, Laju pertumbuhan penduduk Kota Bengkulu yang semakin meningkat di setiap tahunnya perlu suatu tindakan yang cepat pula untuk memprediksi tingkat pertumbuhan penduduk saat ini dan untuk tahun-tahun berikutnya.

Jaringan Syaraf Tiruan merupakan pemodelan data yang kuat yang mampu menangkap dan mewakili hubungan Input-Output yang komplek, karena kemampuannya untuk memecahkan beberapa masalah relatif mudah digunakan, ketahnan untuk mengimput data kecepatn untuk eksekusi, dan menginisialisasikan sistem yang rumit. (Norhamreeza Abdul Hamid, 2011)

Jaringan Syaraf Tiruan Backpropagation memiliki kelebihan karena pembelajarnnya dilakukan berulang-ulang sehingga dapat 
mewujudkan sistem yang tahan akan kerusakan dan konsisten bekerja dngan baik (Anwar, 2011).

Dengan menggunakan Jaringan Syaraf Tiruan Backpropagationini diharapkan dapat memberikan alternatif lain dalam memperkirakan dan memprediksi tingkat pertumbuhan penduduk di Kota Bengkulu pada setiap tahunnya. Dari permasalahan tersebut, maka penulis ingin mengangkat judul penelitian yaitu "Jaringan SyarafTiruan untuk Memprediksi Laju Pertumbuhan Penduduk Dengan Menggunakan Metode BacpropagationStudi Kasus Di Kota Bengkulu".

\section{TINJAUAN PUSTAKA}

\section{A) Jaringan Syraf Tiruan}

Jaringan Syaraf Tiruan (JST) merupakan suatu sistem pemrosesan informasi yang mempunyai karakteristik menyerupai jaringan syaraf biologis (JSB) Jaringan Syaraf Tiruan tercipta sebagai suatu generalisasi model matematis dari pemahaman manusia (human cognition) (Maharani Dessy Wuryandari, 2012)

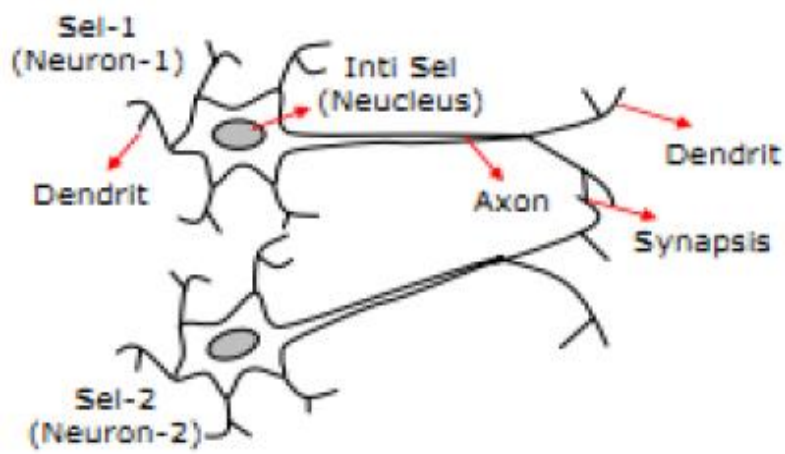

Gambar 1. Syaraf Secara Biologis

\section{B) Model Jaringan Syaraf Tiruan}

Seperti halnya otak manusia, jaringan syaraf juga terdiri dari beberapa neuron, dan terdapat hubungan antara neuron-neuron tersebut. Pada gambar 2. menunjukkan struktur neuron yang mana Neuron-neuron akan mentransformasikan informasi yang diterima melalui sambungan keluarannya menuju ke neuron-neuron yang lain. Pada jaringan syaraf hubungan ini dikenal dengan nama bobot. Informasi tersebut tersimpan pada suatu nilai tertentu pada bobot tersebut.

keduanya atau mungkin lebih untuk mendapatkan redundansi data.

Ini diproses oleh suatu fungsi perambatan yang akan menjumlahkan nilai-nilai semua bobot yang akan datang. Hasil penjumlahan ini kemudian dibandingkan dengan suatu Informasi yang disebut dengan masukkan dikirim ke neurondengan bobot kedatangan tertentu. Masukkan nilai ambang (threshold) tertentu melalui fungsi aktivasi setiap neuron.

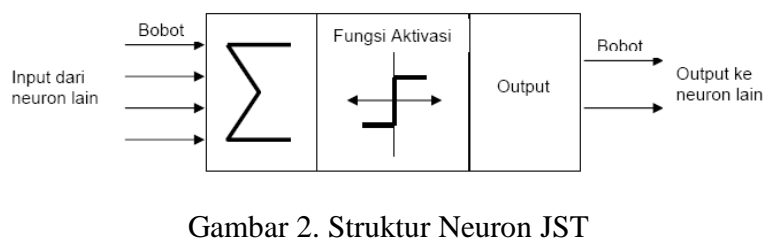

Pada jaringan syaraf, neuron-neuron akan dikumpulkan dalam lapisa -lapisan yang disebut dengan lapisan neuron. Biasanya neuron pada satu lapisan akan dihubungkan dengan lapisan sebelum atau sesudahnya terkecuali lapisan masukkan dan lapisan keluaran. Informasi yang diberikan pada jaringan syaraf akan dirambatkan dari lapisan ke lapisan, melalui dari lapisan masukkan sampai lapisan keluaran melalui lapisan tersembunyi. Algoritma pembelajaran menentukan informasi akan dirambatkan kearah mana, gambar 3 menunjukkan neuron jaringan syaraf sederhana dengan fungsi aktivasi $\mathrm{F}$.

Pada gambar 3 sebuah neuron akan mengolah $\mathrm{N}$ masukkan $\left(\mathrm{X}_{1}, \mathrm{X}_{2}, \mathrm{X}_{3}, \ldots ., \mathrm{X}_{\mathrm{n}}\right)$ yang masing-masing memiliki bobot $\mathrm{W}_{1}, \mathrm{~W}_{2}, \mathrm{~W}_{3}, \ldots, \mathrm{W}_{\mathrm{n}}$ dengan rumus :

$$
y_{-} i n=\sum_{i=1}^{n} x_{i} w_{i} \ldots \ldots \ldots \ldots \ldots
$$

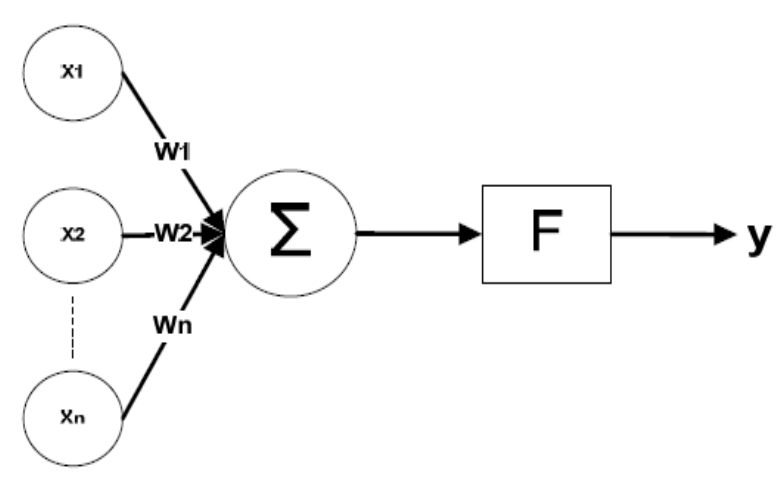

Gambar 3. Model Neuron Sederhana

\section{C) Fungsi Aktivasi}

Merupakan fungsi pengolah jumlahan data input menjadi data output. Karakteristik yang harus ada pada fungsi aktivasi Backpropagation kontinue, dapat diturunkan, kontinue dan tidak menurun 
secara monoton, fungsi aktivasi merupakan lengkung sigmoit (Iskandar Zulkarnain, 2011)

\section{1) Fungsi Sigmoid Biner}

$$
\begin{aligned}
& \mathrm{y}=\mathrm{f}(\mathrm{x})=\frac{1}{1+e^{-\sigma x}} \\
& \mathrm{f}^{\prime}(\mathrm{x})=\sigma \mathrm{f}(\mathrm{x})[1-\mathrm{f}(\mathrm{x})]
\end{aligned}
$$

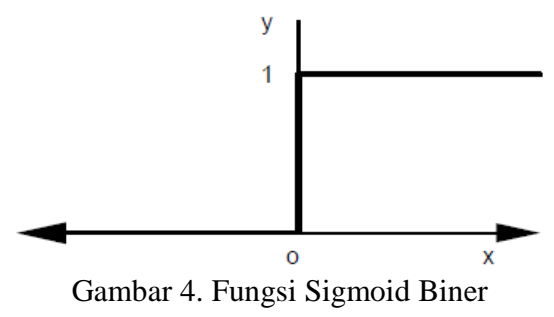

2) Fungsi Linier (Identitas)

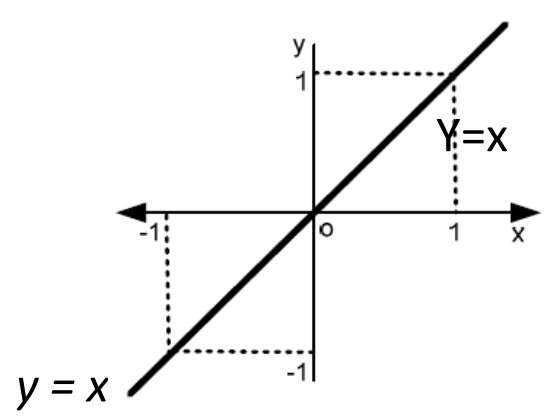

Gambar 5. Fungsi Aktivasi Linear

\section{D) Algoritma Backpropagation}

Perambat galat mundur (Backpropagation) adalah sebuah metode sistematika untuk pelatihan multilayer Jaringan Syaraf Tiruan. Jaringan Backpropagation merupakan salah satu algoritma yang sering digunakan dalam menyelesaikan masalah-masalah yang rumit (Anwar, 2011). Algoritma ini juga dipakai pada aplikasi pengaturan karena proses pelatihannya didasarkan pada hubungan yang sederhana..

\section{E) Arsitektur Backpropagation}

Backpropagation terdiri dari $\mathrm{n}$ buah masukan (ditambah sebuah bias), sebuah layar tersembunyi yang terdiri dari p unit (ditambah sebuah bias), serta $\mathrm{m}$ buah unit keluaran. $\mathrm{V}_{\mathrm{oj}}$ dan $\mathrm{W}_{\mathrm{ok}}$ masing-masing adalah bias untuk unit tersembunyi ke-j dan untuk output ke-k. Bias $\mathrm{V}_{\mathrm{oj}}$ dan $\mathrm{W}_{\mathrm{ok}}$ berperilaku seperti bobot dimana output bias ini selalu sama dengan 1 .

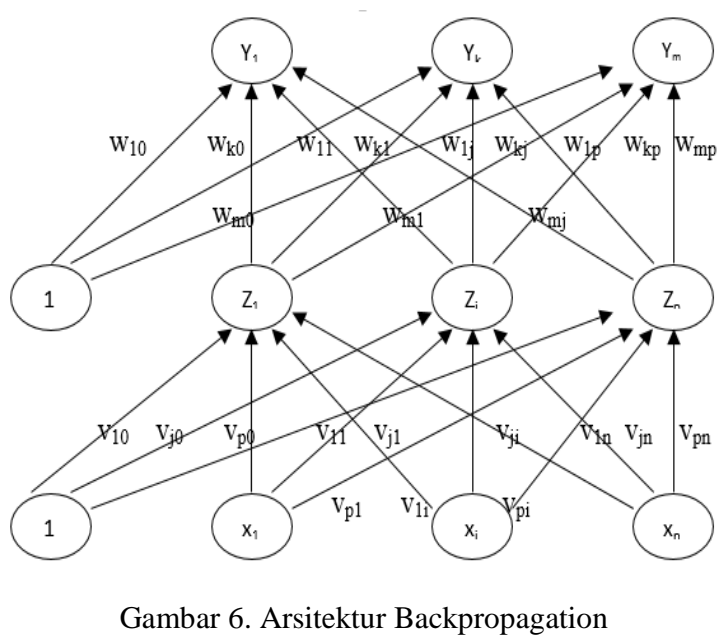

\section{F) 2.6 Pengertian Peramalan}

Peramalan adalah proses untuk memperkirakan berapa kebutuhan dimasa yang akan datang yang meliputi kebutuhan dalam ukuran kuantitas, kualitas, waktu dan lokasi yang dibutuhkan dalam rangka memenuhi permintaan barang ataupun jasa.(Pakaja et al., 2013)

\section{G) Pengertian Penduduk}

Penduduk adalah semua orang ang berdomisili di wilayah geografis Indonesia selama enam bulan atau lebih dan atau mereka yang berdomisili kurang dari enam bulan tetapi bertujuan menetap. Pertumbuhan penduduk diakibatkan oleh tiga komponen yaitu: fertilitas, mortalitas dan migrasi.

Pertumbuhan penduduk adalah angka yang menunjukkan tinkat pertambahan penduduk pertahun dalam jangka waktu tertentu (Safarul Aufa, 2013).

\section{METODOLOGI PENELITIAN}

\section{A) Metodologi Penelitian}

Merupakan langkah-langkah kerja yang perlu dilakukan agar penulisan tesis menjadi lebih mudah. Metodologi yang digunakan dalam penulisan tesis ini dalah pengumpulan data. Datadata yang dikumpulkan kemudian diidentifikasi masalah dan disesuaikan dengan kebutuhan. serta cara kerja dan ruang lingkup sistem yang akan dibuat.

Penelitian adalah rangkaian kegiatan ilmiah dalam rangka pemecahan suatu permasalahan. Fungsi penelitian adalah mencarikan penjelasan dan jawaban terhadap permasalahan serta dapat memberikan solusi atau alternatif bagi kemungkinan yang dapat digunakan untuk pemecahan masalah. Penjelasan dan jawaban 
terhadap penjelasan itu dapat bersifat abstrak dan umum sebagai mana halnya dalam penelitian dasar yang kongkrit dan spesifik seperti biasanya ditemukan dalam penelitian.

\section{B) Kerangka Kerja}

Di sini diuraikan metodologi dan kerangka kerja penelitian digunakan untuk mengambarkan langkah-langkah yang akan diterapkan dalam melakukan penelitian. Hal ini diterapkan supaya penelitian ini dapat dilakukan secara terstruktur. Langkah-langkah yang digunakan harus mencakup mulai darai mempelajari masalah sampai dengan adanya suatu sistem yang dapat dihasilkan sehingga masalah dapat dipecahkan. Maka pada tesis ini diterapkan beberapa tahapan yang dilakukan terlihat pada Gambar 7.

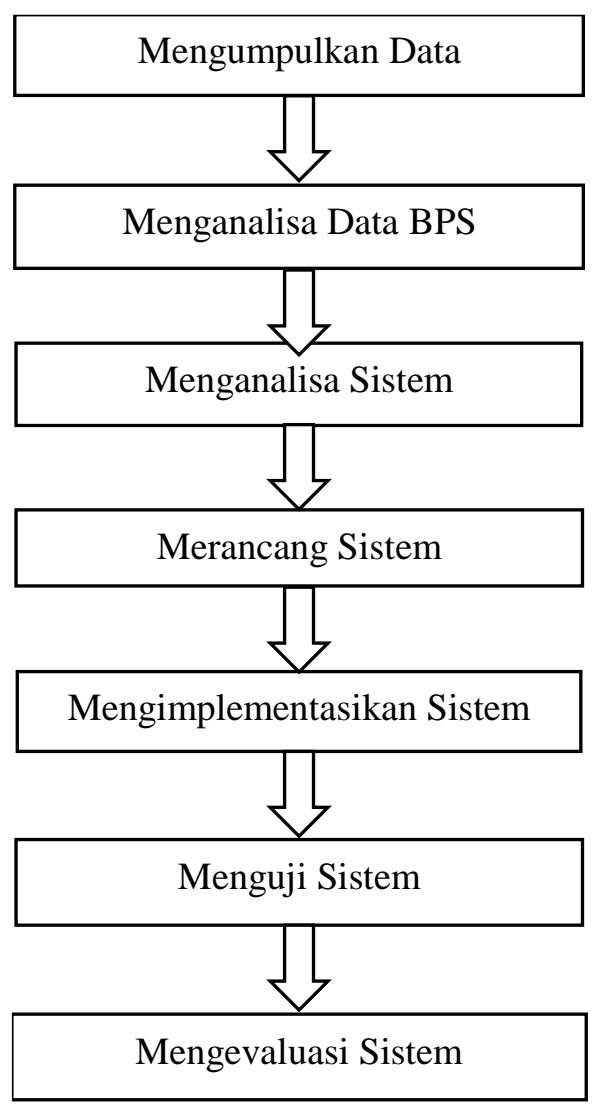

Gambar 7. Kerangka Kerja Penelitian

\section{PEMBAHASAN}

\section{A) Analisa Sampel Dan Penentuan Pola}

Menentukan sampel berdasarkan beberapa kriteria di mana kriteria yang ditentukan ini meliputi sampel data yang didapat dari BPS, data yang diambil meliputi data jumlah penduduk laki-laki dan data jumlah penduduk perempuan perkecamatan dari tahun 2010 sampai tahun 2014, kemudian data tersebut disajikan dalam bentuk tabel data normalisasi.

\section{B) Faktor-Faktor Yang Mempengaruhi Laju Pertumbuhan Penduduk}

Dalam menentukan jumlah pertumbuhan penduduk yang dilakukan pada setiap 10 tahunnya dipengaruhi oleh beberapa faktor, yaitu faktor kelahiran,kematian dan migrasi, namun perhitungan penduduk pada setiap tahunnya dihitung dari umur dan jenis kelamin hal ini disebabakan oleh tidak pernah adanya laporan kelahiran dan kematian pada setiap tahunnya, angka kematian dan kelahiran ini biasanya dapat diketahui ketika diadakannya sensus penduduk pada setiap 10 tahun sekali.

\section{C) Pemodelan JST Untuk Prediksi Pertumbuhan Penduduk}

\section{1) Variabel Masukan}

Agar data dapat dikenali oleh jaringan dan sekaligus dapat diproses menggunakan perangkat lunak (software) maka data harus diubah kedalam bentuknumerik. Di dalam penelitian ini variabel masukan dalam memprediksi laju pertumbuhan penduduk terdiri dari jumlah penduduk menurut umur dan jenis kelamin.

\section{2) Data Input dan target}

Ada beberapa hal yang harus didefinisikan dalam menerapkan Jaringan Syaraf Tiruan untuk memprediksi laju pertumbuhan penduduk, yaitu: Nilai input yang akan dimasukkan pada sistem dalam bentuk angka-angka yang telah diinisialisasikan dalam sistem. Sistem akan melakukan pengolahan data apakah output akan sama dengan yang diharapkan atau tidak. Sebagai Input dalam prediksi pertumbuhan penduduk ini adalah berdasarkan umur jumlah penduduk laki-laki dan jumlah penduduk perempuan.

\section{D) Arsitektur Jaringan}

Pada umumnya, neuron-neuron yang terletak pada lapisan yang sama akan memiliki keadaan yang sama. Faktor terpenting dalam menentukan kelakuan suatu neuron adalah fungsi aktivasi dan pola bobotnya.

Arsitektur jaringan adalah sebuah arsitektur yang menentukan pola antar neuron. Di mana neuron-neuron tersebut terkumpul dalam lapisan- 
lapisan yang disebut neuron layer, lapisan penyusun Jaringan Syaraf Tiruan dibagi menjadi tiga. Dalam kasus ini Arsitektur Jaringan Syaraf Tiruan yang digunakan adalah jaringan Backpropagation yaitu:

1) Lapisan Input (Input Layer), adalah unit-unit dalam lapisan input disebut unit-unit input yang bertugas menerima pola inputan dari luar yang menggambarkan suatu permasalahan dengan 2 simpul.

2) Lapisan tersembunyi (hidden layer), adalah unit-unit dalam lapisan tersembunyi disebut unit-unit tersembunyi yang mana nilai-nilai output-nya tidak dapat diamati secara langsung. Jumlah simpul yang ditentukan oleh pengguna.

3) Lapisa output (output layer), adalah unit-unit dalam lapisan output disebut unit-unit output, yang merupakan solusi Jaringan Syaraf Tiruan terhadap suatu permasalahan. Terdiri dari 1 simpul yaitu jumlah dari semua variabel lakilaki dan perempuan sebagai nilai yang diprediksi.

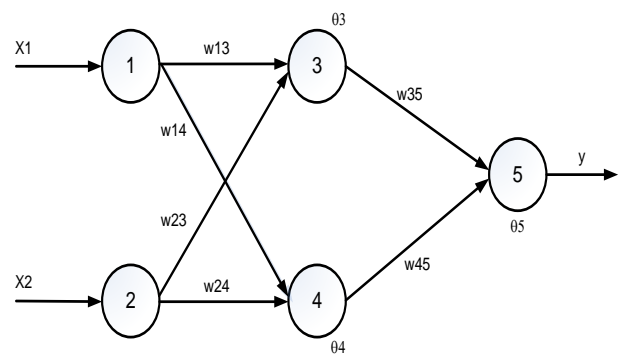

Gambar 8. Arsitektur JST Untk Prediksi Pertumbuhan Penduduk

\section{E) Normalisasi Data Penduduk}

Dalam prediksi terhadap pertumbuhan penduduk ada 2 faktor yang mempengaruhinya yaitu jumlah penduduk laki-laki dan penduduk perempuan. Kedua faktor tersebut digunakan karena dianggap mempunyai pengaruh yang paling signifikan terahap jumlah pertumbuhan penduduk. Lapisan input terdiri dari 2 unit dan datanya diambil dari tahun 2010 sampai dengan tahun 2014 Dapat dilihat pada tabel 1 .

Tabel 1. Data Penduduk

\begin{tabular}{|c|c|c|c|}
\hline No & $\mathrm{X} 1$ & $\mathrm{X} 2$ & Target \\
\hline 1 & 13,39 & 9,94 & 23,33 \\
\hline 2 & 15,55 & 13,15 & 28,7 \\
\hline 3 & 14,38 & 12,66 & 27,04 \\
\hline 4 & 15,43 & 16,29 & 31,72 \\
\hline 5 & 12,96 & 16,39 & 29,35 \\
\hline 6 & 13,51 & 13,79 & 27,3 \\
\hline
\end{tabular}

Jaringan Syaraf Tiruan...
Berdasarkan data tabel 1 Algoritma Propagasi Balik (Backpropagation) ini akan dipakai fungsi aktivasi sigmoid karena pada fungsi aktivasi sigmoid nilai fungsinya terletak antara 0 dan 1 kemudian data tersebut ditransformasikan dulu ke interval yang lebih kecil, misalnya pada interval $[0.1,0.9]$ sesuai rumus pada BAB 2 .

Setelah proses normalisasi maka data terkecil akan menjadi 0.1 dan data terbesar akan menjadi 0.9 hasil normalisasidata pada tabel 4.2 diatas dapat di tunjukkan pada tabel 4.3 yang nanatinya dipakai sebagai data pelatihan Backpropagation.

Adapun langkah awal dalam menentukan proses normalisasi data adalah dengan cara menentukan data yang akan dinormalkan (X), lalu menentukan nilai yang paling tinggi dan nilai paling rendah dari data yang ada, yaitu sebagai berikut:

X1 Nilai Maximal $=939$

$$
\text { Nilai Minimal }=1,042
$$

Dengan persamaan normalisasi di atas, maka akan didapat:

$$
X 1=\frac{(13,39-1,042) *(1-0)-0}{939-1,024}=0,0132
$$

Tabel 2.Normalisasi Data Penduduk

\begin{tabular}{|c|c|c|c|c|c|}
\hline \multirow{2}{*}{$\mathrm{X} 1$} & \multicolumn{2}{|c|}{ Normalisasi } & \multicolumn{2}{c|}{ Normalisasi } & Normalisasi \\
\cline { 2 - 6 } & $\mathrm{X} 1$ & $\mathrm{X} 2$ & $\mathrm{X} 2$ & Target & Target \\
\hline 13,39 & 0,0132 & 9,94 & 0,4573 & 23,34 & 0,5546 \\
\hline 15,55 & 0,0155 & 13,15 & 0,6206 & 28,70 & 0,6944 \\
\hline 14,38 & 0,0142 & 12,66 & 0,5957 & 27,04 & 0,6511 \\
\hline 15,43 & 0,0153 & 16,29 & 0,7804 & 31,72 & 0,7732 \\
\hline 12,96 & 0,0127 & 16,39 & 0,7855 & 29,34 & 0,7111 \\
\hline 13,51 & 0,0133 & 13,79 & 0,6532 & 27,30 & 0,6579 \\
\hline
\end{tabular}

\section{F) Pemodelan Algoritma Backpropagation}

Langkah-langkah penggunaan algoritma propagasi balik dengan menggunakan fungsi aktivasi sigmoid adalah sebagai berikut:

\section{1) Tahap Initialization}

Merupakan tahapan untuk mendefinisikan/ menset awal nilai untuk variabel-variabel yang diperlukan seperti; nilai input, weight, output yang diharapkan, learning rate $(\alpha), \theta$ dan sebagainya.

\section{2) Tahap Activation}

Pada tahap activation ini dilakukan 2 (dua) kegiatan yaitu; menghitung actual output pada hidden layer dan menghitung actual output pada output layer. 


\section{3) Tahap Weight Training}

Pada tahap weight training ini juga dilakukan 2 (dua) kegiatan yaitu; menghitung error gradient pada output layer dan menghitung error gradient pada hidden layer.

\section{4) Tahap Iteration}

Tahapan terakhir ini adalah tahapan untuk pengujian dimana jika error yang diharapkan belum ditemukan maka akan kembali lagi kepada tahapan ke 2 (dua) activation.

Sebagai contoh perhitungan pelatihan/ peramalan dengan Jaringan Syaraf Tiruan pada prediksi pertumbuhan penduduk menggunakan 2 buah variabel input vektor inputx. yaitu :

$$
\begin{aligned}
& \mathrm{x}_{1}=\text { Jumlah Laki-laki } \\
& \mathrm{x}_{2}=\text { Jumlah Perempuan. }
\end{aligned}
$$

\section{G) Perancangan Parameter}

Untuk melakukan pelatihan terhadap Jaringan Syaraf Tiruan dengan menggunakan Matlab ditentukan parameter berikut ;

1) Parameter Epoch adalah 20000

2) Parameter Show Epoch adalah 100

3) Parameter goal adalah 1-e-2/ 0.01

4) Parameter ir adalah 0.5

5) Parameter mc adalah 0.8

6) Fungsi Aktivasi dengan menggunakan Sigmoid Biner range 0 dan 1.

\section{H) Pelatihan dan Pengujian}

Pelatihan Backpropagation meliputi tiga fase yaitu fase maju di mana masukan dihitung maju mulai dari layer masukan hingga layer keluaran dengan menggunakan fungsi aktivasi yang ditemukan. Fase kedua adalah fase mundur, di mana selisih antara keluaran dengan target. Fase ketiga adalah modifikasi bobot untuk menurunkan kesalahan yang terjadi.

Pada proses perhitungan algoritma backpropagation dalam Jaringan Syaraf Tiruan, terlebih dahulu dilakukan bobot awal (diambil random yang cukup kecil). Bobot awal yang menghubungkan simpul - simpul pada lapisan input dan lapisan tersembunyi untuk arsitektur di atas adalah $w=(w 15, w 16, w 17, w 18, w 25, w 26, \ldots \ldots w 89)$ dan bobot bisa dipilih secara acak. Demikian pula bobot - bobot awal yang menghubungkan simpul - simpul pada lapisan tersembunyi dan lapisan output $(w t, w 2)$ dipilih secara acak.

\section{1) Tahap Initialitation}

Merupakan tahapan untuk mendefinisikan nilai awal untuk variabel-variabel yang diperlukan seperti ; input, weight, output yang diharapkan, learning rate $(\alpha), \theta$ dan sebagainya.

Bobot awal merupakan gabungan - gabungan pada lapisan input tersembunyi dan lapisan output untuk menentukan target. Mula - mula bobot diberi nilai acak kecil range $(0,1)$ sebagai berikut.

$\begin{array}{llll}\text { Tahap } & \text { 1. Initialitation } & & \\ \mathrm{x}_{1} & =0,0132 & \mathrm{x}_{2}=0,4573 & \\ \mathrm{j} & =3 \mathrm{~s} / \mathrm{d} 4 & \mathrm{k}=5 & \\ \mathrm{w}_{13} & =0,5 & \mathrm{w}_{23}=0,4 & \mathrm{w}_{35}=-1,2 \\ \mathrm{w}_{14} & =0,9 & \mathrm{w}_{24}=1,0 & \mathrm{w}_{45}=1,1 \\ \theta 3 & =0,8 & \theta 4=-0,1 & \theta 5=0,3\end{array}$

Learning Rate $(\alpha)=0,1 \quad$ Disered output $(\mathrm{Yd})=0$

\section{Tahap 2. Activation (iterasi $P=1$ )}

Dalam Backpropagation, fungsi aktivasi yang dipakai harus memenuhi beberapa syarat yaitu: Kontinu, terdiferensial dengan mudah dan merupakan fungsi yang tidak turun. Salah satu fungsi yang memenuhi ketiga syarat tersebut sehingga sering dipakai adalah fungsi sigmoidbiner yang memiliki range $(0,1)$. Pada tahap activation ini dilakukan 2 kegiatan yaitu: menghitung actual output pada hidden layer dan menghitung actual output pada output layer.

\section{I) Matlab}

Matlab adalah software buatan the mathwork inc, yang sangat bermanfaat untuk menyelesaikan berbagai masalah numerik, perangkat lunak ini menawarkan kemudahan dan kesederhanaan dalam menyelesaikan masalah yang berhubungan dengan vektor dan matriks. Memperoleh inversi matriks dan menyelesaikan persamaan linier merupakan contoh permasalahan yang dapat dipecahkan dengan cara yang sangat singkat dan mudah sekali.

\section{J) Pengujian}

Implementasi pengolahan data penelitian menggunakan Matlab (matrix Laboratory) di mana Matlab menyediakan fungsi-fungsi khusus untuk 
menyelesaikan model Jaringan Syaraf Tiruan, pemakai hanya tinggal memasukkan vector masukan, target, model dan parameter diinginkan. Tujuan pengujian perangkat lunak ini adalah untuk membuktikan bahwa arsiktektur jaringan yang dibangun terutama pada kasus prediksi pertumbuhan penduduk diaplikasikan pada perangakat lunak yang dipilih yaitu Matlab.

\section{K) Proses Pengujian Arsitektur 2-3-1, Trainscg}

Yaitu melakukan proses pengaturan max epoch, goal, learning rate, show step untuk proses pembelajaran terhadap data yang diolah seperti perintah di bawah ini:

Pengujian Jaringan Syaraf Tiruan dengan arsitektur 2-3-1 dengan perintah seperti dibawah ini:

$$
\begin{aligned}
& \text { > }>\text { net.trainParam.epochs }=20000 ; \\
& \text { > } \text { net.trainParam.goal }=1 \mathrm{e}-2 ; \\
& \text { > } \text { net.trainParam.Ir }=0,5 ; \\
& \text { > } \text { net.trainParam.show }=50 ; \\
& \text { > } \text { net.trainParam.mc }=0,8 ; \\
& \text { > }>\text { net.trainParam.(net,pn,tn) }
\end{aligned}
$$

Dari proses pelatihan di atas dilakukan fungsi pelatihan TrainScg, dengan 2 input, 3 hidden layer dan 1 output. dapat dilihat seperti terlihat pada gambar 9.

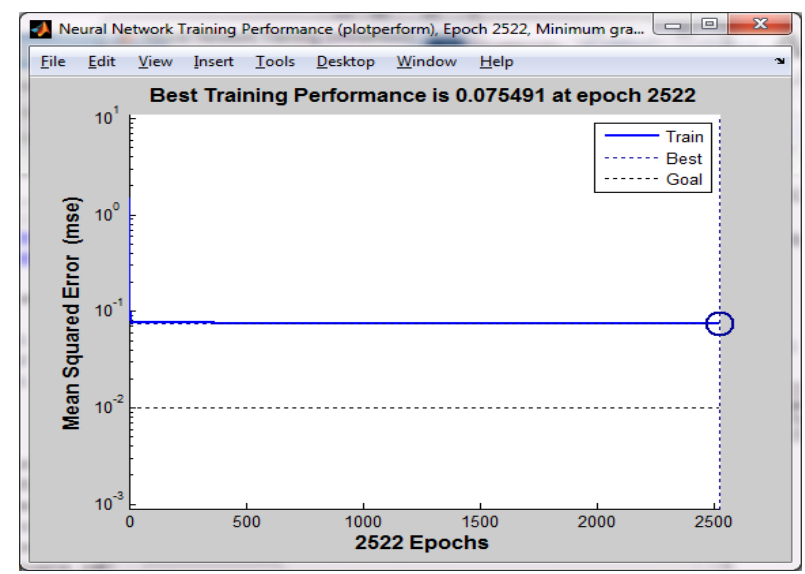

Gambar 9. Hasil Pelatihan 2-3-1

Pada Gambar 5.1 merupakan hasil dari pelatihan pola 2-3-1 yang nilai performance terbaiknya terlihat pada epochs 2522, dengan best validition performance 0,075491 .

\section{1) Menampilkan bobot awal yang diperoleh} > bobotAwal=net.iw $[1,1]$

bobotAwal $=$

$$
-0.1890 \quad 1.3614
$$

$$
0.3564-1.2825
$$$$
0.3869-1.2621
$$

>> bobotAwal_Lapisan=net.lw[2,1]

bobotAwal_Lapisan =

$\begin{array}{lll}-0.3608 & 0.0617 & 0.3089\end{array}$

>> bobotAwal_bias1=net.b[2,1]

bobotAwal_bias1 =

$-0.1848$

> bobotAwal_bias2=net.b[1,1]

bobotAwal_bias $2=$

2.6537

$-0.6407$

1.7079

\section{2) Evaluasi Output Jaringan (Data Pelatihan dengan Target)}

Output jaringan dan target dianalisis dengan regresi linier dengan mengggunakan postreg, melihat nilai error atau selisih antara nilai target dan output, evaluasi output jaringan (data pelatihan dengan target).

$$
\begin{gathered}
>>[\mathrm{m} 1, \mathrm{a} 1, \mathrm{r} 1]=\operatorname{postreg}(\mathrm{a}, \mathrm{t}) \\
\mathrm{m} 1=0.9235, \mathrm{a} 1=-7.6612 \mathrm{e}-08, \mathrm{r} 1=0.9610
\end{gathered}
$$

Korelasi bernilai 0,9610 mendekati 1 (satu) menunjukkan hasil yang baik untuk kecocokan nilai target dan output.

>>plot([1:size(P,2)]',T,'bo',[1:size(P,2)]',a','r*');

$>>$ title('Hasil Pengujian Dengan Data Pelatiha: Target(o), Output (*)');

>>xlabel('DataKe-');ylabel('Target/Output');pause

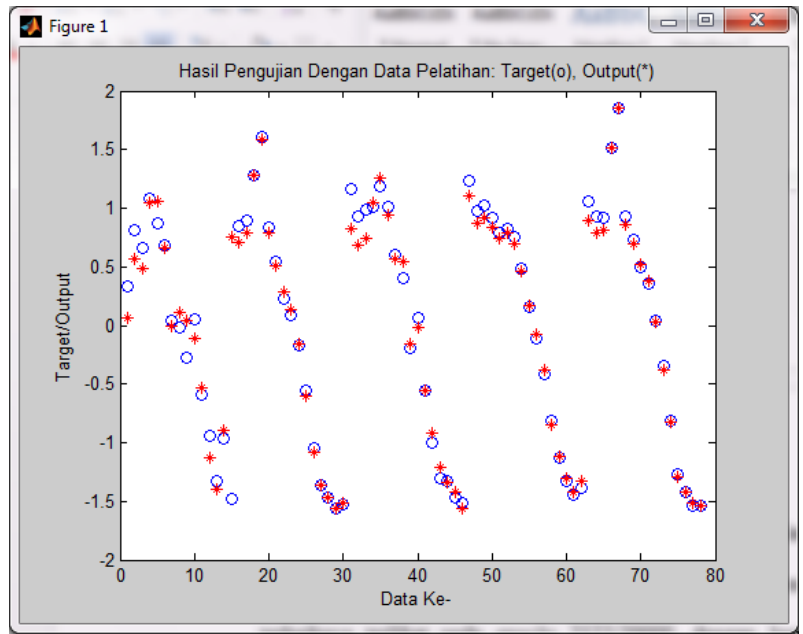

Gambar 10. Antarmuka Hubungan Antara Target dan Output 
Melihat dari korelasi 0.9610 menunjukkan prediksi jumlah penduduk berdasarkan data selama 5 tahun kurang baik, pada data diatas terlihat bahwa error terkecil ditunjukkan data ke- 67 yaitu sebesar $-0,0005$ dan error terbesar pada data ke- 1 yaitu sebesar 0,2687 nilai MSE dari akhir pelatihan sebesar 0,075491 .

\section{PENUTUP}

\section{A) Kesimpulan}

Dari hasil pembahasan dan pengujian dengan menggunakan Software Matlab, maka dapat ditarik kesimpulan sebagai berikut:

1) Jarinngan yang digunakan terdiri dari tiga buah lapisan yaitu lapisan input, lapisan tersembunyi dan lapisan keluaran.

2) Algoritma Backpropagation dapat melakukan proses prediksi, akan tetapi baik atau tidaknya nilai yang dihasilkan sangat dipengaruhi oleh penentuan parameter besarnya Learning Rate dan jumlah neuron pada HiddenLayer.

3) Semakin besar jumlah unit dalam hidden layer maka hasil prediksi akan semakin mendekati nilai yang ditargetkan.

4) Terdapat beberapa faktor yang mempengaruhi tingkat kebenaran prediksi pada Jaringsn Syaraf Tiruan Backpropagation yaitu learning rate, target error, jumlah data dan nilai bobot yang diberikan secara random pada tiap-tiap neuron.

5) Dengan learning rate dan target error untuk pembelajaran yang sama belum tentu menghasilkan tingakat prediksi yang sama juga,hal ini dikarenakan nilai bobot-bobot pada tiap neuron yang dihasilkan oleh setiap pembelajaran berbeda. karena disebabkan oeleh pemberian nilai bobot awal dengan nilai random, di mana nilai random setiap pembalajaran berbeda.

6) Jaringan Syaraf Tiruan dengan bantuan Software Matlab dapat memprediksi jumlah laju pertumbuhan penduduk.

7) Perangkat lunak Matlab telah berhasil melakukan serangkaian tahapan yang diperlukan dalam prediksi laju pertumbuhan penduduk.

8) Penelitian ini telah memberikan kontribusi pada persoalan pengambilan keputusan terhadap perhitungan laju pertumbuhan penduduk di Kota Bengkulu.

\section{B) Saran}

Berdasarkan pengamatan yang dilakukan agar penelitian yang akan dilakukan selanjutnya lebih baik lagi maka penulis menyarankan sebagai berikut:

1) Berdasarkan pada kesimpulan, disarankan agar diadakan penelitian lebih lanjut.

2) Prediksi jumlah laju pertumbuhan penduduk dilakukan dengan metode yang lain misalnya mnggunakan fuzzy atau yang lainnya.

3) Perlu dikembangkan penelitian yang lebih mendalam dan variasi algoritma pelatihan supaya mendapatkan hasil yang lebih optimal dengan waktu pelatihan yang lebih singkat lagi.

4) Lapisan tersembunyi lebih dari satu dan parameter yang digunakan di set lebih tepat lagi agar jaringan dapat mengenali pola semua pola data input. Agar dapat memprediksi dengan lebih akurat.

\section{DAFTAR PUSTAKA}

Anwar, B. 2011. Penerapan Algoritma Jaringan Syaraf Tiruan Backpropagation Dalam Memprediksi Tingkat Suku Bunga Bank. Jurnal SAINTIKOM, Vol. 10 / No. 2.

Maharani Dessy Wuryandari, I. A. 2012. Perbandingan Metode Jaringan Syaraf Tiruan Backpropagation Dan Learning Vector Quantization Pada Pengenalan Wajah. Jurnal Komputer dan Informatika (KOMPUTA), Edisi. I Volume. 1.

Norhamreeza Abdul Hamid, N. M. N., Rozaida Ghazali, Mohd Najib Mohd Salleh 2011. Accelerating Learning Performance of Back Propagation Algorithm by Using Adaptive Gain Together with Adaptive Momentum and Adaptive Learning Rate on Classification Problems. International Journal of Software Engineering and Its Applications, Vol. 5 No. 4.

Pakaja, F., Naba, A. \& Purwanto, P. 2013. Peramalan Penjualan Mobil Menggunakan Jaringan Syaraf Tiruan dan Certainty Factor. Jurnal EECCIS, 6, pp. 23-28. 
Safarul Aufa, R. M., Muhammad Nasir 2013. Pengaruh Pendapatan Perkapita, Pertumbuhan Penduduk, Dan Tingkat Upah Terhadap Biaya Hidup Di Indonesia. Jurnal Ilmu Ekonomi, Volume 1, No. 1. 